\section{Stabilization of Microcirculation in Patients with Early Systemic Sclerosis with Diffuse Skin Involvement following Rituximab Treatment: An Open-label Study}

\section{To the Editor:}

Systemic sclerosis ( $\mathrm{SSc}$ ) is a multisystemic autoimmune disease characterized by fibrosis of the skin and internal organs, generalized microvasculopathy, and antibody response against various cellular antigens. Severe organ involvement occurs early in the course of diffuse cutaneous SSc $(\mathrm{dcSSc})$ and has a bad prognosis ${ }^{1}$. Survival of the first years of the disease is associated with improved outcome. Therapies that may help the patient overcome this early period seem warranted ${ }^{2}$. Rituximab (RTX) has been reported as optional therapy in $\mathrm{SSc}^{3,4,5}$. Our group reported stabilization of internal organ involvement during a 2-year followup in an open pilot study of a 2-treatment course (months 0 and 6) of RTX in patients with early $\mathrm{dcSSc}^{6,7}$. In our pilot studies, modified Rodnan skin score (mRSS) decreased significantly after RTX course. The percent of decrease in the open pilot studies was corroborated by a similar decrease in the percentage of collagen score in blindly assessed histopathological skin analyses.

Because SSc is characterized by a pronounced microangiopathy over time (i.e., more severe loss of capillaries over time), it may be worthwhile to investigate whether treatment with RTX could also stabilize microangiopathy in $\mathrm{dcSSc}^{8,9}$. Nailfold videocapillaroscopy (NVC) is a reliable technique to evaluate the microcirculation (capillaries) in $\mathrm{SSc}^{10}$. Subsequent to the former studies, our additional study described herein, using the same design as the already published studies, is the first (to our knowledge) to assess microangiopathic evolution after a 2-treatment course (months 0 and 6) with RTX in early dcSSc${ }^{6,7}$. Six consecutive patients with "early" (see below) dcSSc received an infusion of 2 times $1000 \mathrm{mg}$ RTX at months 0 and 6, together with $100 \mathrm{mg}$ methylprednisolone. Low-dose prednisolone ( $\leq 10 \mathrm{mg} /$ day) was allowed, provided that the patients were taking a stable dose at least 12 weeks before inclusion in the trial. All disease-modifying antirheumatic drugs [except methotrexate (MTX)] were stopped 12 weeks before screening ${ }^{6,7}$. Patients ( 5 men and 1 woman) were receiving a stable dose of MTX (10-25 mg/week) as background therapy since at least 12 weeks. Their median age was 49 years (range 37-64 yrs) and their median SSc disease duration was 11 months (range 5-22 mos, from onset of the first non-Raynaud phenomenon). Four of the 6 patients were anti-scl70-positive and $1 / 6$ was RNA-polymerase-positive.
Nailfold capillaries were imaged using a nailfold videocapillaroscope with high magnification (200x) in 8 fingers (f), f2-5 of both hands, at months $0,3,6$, and 12 . The number of capillaries in the distal row were recorded, as well as the number of giants and hemorrhages, and the number of abnormally shaped [(neo)angiogenetic] capillaries. Scores were calculated, as described previously ${ }^{9}$. The observers evaluating the capillaroscopic images (CP, VR) were blinded to the study design and subjects' identity. Next to capillaroscopic assessment, clinical readouts (mRSS, lung function, and echocardiography) and Disease Activity Score (DAS) were done at 0 , 3,6 , and 12 months $^{6,7}$. Mixed-model analysis (MMA) with random intercept for patient was used to evaluate changes in variables over time. A statistical significance level of 0.05 was used.

There was a clinical significant change in skin score with a mean (SD) mRSS of 24.8 (5.95) at baseline and 10.2 (1.17) at Month 12 (MMA p < 0.001 , mean/median \% improvement: $59 \% / 60 \%$ ) and a significant decrease in DAS, with a mean (SD) of $4.2(1.69)$ at baseline and $0.6(0.74)$ at Month 12 (MMA p $<0.001$, mean/median \% improvement: 86\%/87\%). Indices of internal organ involvement remained stable (Table 1).

Semiquantitatively scored NVC variables remained stable, showing no progression of the microvascular damage during the 12-month followup (Table 2) ${ }^{9}$. More specifically, whereas more pronounced loss of capillaries was expected over time, the number of capillaries remained stable ${ }^{8}$. In this way, the mean score (SD) of capillary loss at baseline/12 months was 2.170 $(0.408) / 1.830(0.408$, MMA $p=0.341)$. There was also no significant change in the number of other scleroderma type morphological characteristics (giants, hemorrhages, and neoangiogenesis) over time (Table 2). There was 1 serious adverse event, a scleroderma renal crisis. It occurred before the first RTX infusion and was considered probably unrelated to the study medication. It reacted well to angiotensin-converting enzyme inhibitors without need for renal replacement therapy, further bouts, or deterioration during the 12-month followup.

To our knowledge, ours is the first open pilot study to suggest that 2 immunosuppressive treatment courses with RTX, while receiving background stable MTX, may not only have potential efficacy for skin and stabilization of internal organ involvement, but also additional stabilization of microangiopathic variables in early dcSSc. Larger, randomized controlled trials are needed to further investigate these findings.

Table 1. Changes in clinical variables in patients with early and severe diffuse cutaneous systemic sclerosis treated with rituximab $(n=6)$. Data are mean $(\mathrm{SD})$, median (IQR).

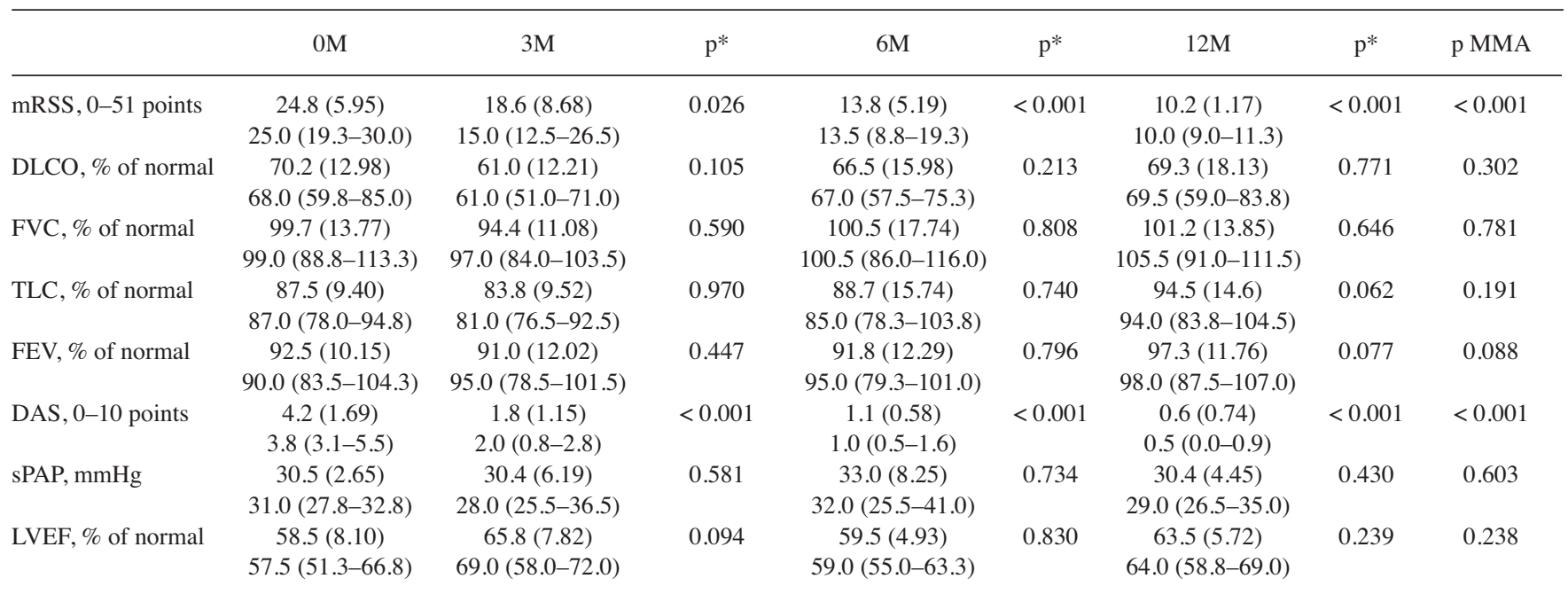

* Significance of all values versus baseline. M: month; MMA: mixed-model analysis; mRSS: modified Rodnan skin score; FVC: forced vital capacity; TLC: lung total capacity; FEV: forced expiratory volume; DAS: Disease Activity Score; sPAP: systolic pulmonary artery pressure; LVEF: left ventricular ejection fraction; IQR: interquartile range. 
Table 2. Microangiopathic evolution (SQ scores) in patients with early and severe diffuse cutaneous systemic sclerosis treated with rituximab $(\mathrm{n}=6)$. Data are mean (SD), median (IQR).

\begin{tabular}{|c|c|c|c|c|c|c|c|c|}
\hline & $0 \mathrm{M}$ & $3 \mathrm{M}$ & $\mathrm{p}^{*}$ & $6 \mathrm{M}$ & $\mathrm{p}^{*}$ & $12 \mathrm{M}$ & $\mathrm{p}^{*}$ & p MMA \\
\hline \multirow[t]{2}{*}{ SQ capillary loss } & $2.17(0.408)$ & $2.20(0.447)$ & \multirow[t]{2}{*}{0.915} & $2.17(0.753)$ & \multirow[t]{2}{*}{1.000} & $1.83(0.408)$ & \multirow[t]{2}{*}{0.147} & \multirow[t]{2}{*}{0.341} \\
\hline & $2.0(2.0-2.3)$ & $2.0(2.0-2.5)$ & & $2.0(1.8-3.0)$ & & $2.0(1.8-2.0)$ & & \\
\hline SQ giants & $1.0(0.0-1.0)$ & $1.0(0.0-1.0)$ & 0.122 & $1.0(0.0-1.0)$ & 0.090 & $1.0(1.0-1.3)$ & 0.016 & 0.093 \\
\hline \multirow[t]{2}{*}{ SQ hemorrhages } & $0.67(0.516)$ & $0.80(0.447)$ & \multirow[t]{2}{*}{0.590} & $0.83(0.408)$ & \multirow[t]{2}{*}{0.463} & $1.00(0.000)$ & \multirow[t]{2}{*}{0.154} & \multirow[t]{2}{*}{0.529} \\
\hline & $1.0(0.0-1.0)$ & $1.0(0.5-1.0)$ & & $1.0(0.8-1.0)$ & & $1.0(0.0-1.0)$ & & \\
\hline
\end{tabular}

* P value versus baseline. SQ: semiquantitative; M: month; MMA: mixed-model analysis; IQR: interquartile range.

VANESSA SMITH, PhD, Associate Professor of Rheumatology, Head of Clinics, Department of Internal Medicine, Faculty of Medicine and Health Sciences, Ghent University, and Department of Rheumatology, Ghent University Hospital, Ghent, Belgium; CARMEN PIZZORNI*, PhD, Assistant Professor of Rheumatology, Research Laboratory and Academic Division of Clinical Rheumatology, Department of Internal Medicine, University of Genoa, Genoa, Italy; VALERIA RICCIERI*, PhD, Assistant Professor of Rheumatology, Department of Internal Medicine and Medical Specialties, Sapienza University, Rome, Italy; SASKIA DECUMAN*, MSc, Academic Assistant, Department of Internal Medicine, Faculty of Medicine and Health Sciences, Ghent University, Ghent, Belgium; GUY BRUSSELLE, PhD, Senior Full Professor in Respiratory Diseases, Head of Clinics, Department of Respiratory Medicine, Ghent University Hospital, Ghent, Belgium; MICHEL DE PAUW, MD, Cardiologist, Department of Cardiology, Ghent University Hospital, Ghent, Belgium; ELLEN DESCHEPPER, PhD, Statistician, Department of Public Health, Biostatistics Unit, Ghent University, Ghent, Belgium; YVES PIETTE, MD, Rheumatologist, Department of Rheumatology, Ghent University Hospital, Ghent, Belgium; BARBARA RUARO, MD, Trainee of Rheumatology, Research Laboratory and Academic Division of Clinical Rheumatology, Department of Internal Medicine, University of Genoa, Genoa, Italy; ALBERTO SULLI, PhD, Associate Professor of Rheumatology, Research Laboratory and Academic Division of Clinical Rheumatology, Department of Internal Medicine, University of Genoa, Genoa, Italy; ELS VANDECASTEELE, MD, Cardiologist, Department of Cardiology, Ghent University Hospital, Ghent, Belgium; KARIN MELSENS, MSc, Trainee of Rheumatology, Department of Internal Medicine, Ghent University, Ghent, Belgium; FILIP DE KEYSER*, PhD, Senior Full Professor of Rheumatology, Department of Internal Medicine, Faculty of Medicine and Health Sciences, Ghent University, and Department of Rheumatology, Ghent University Hospital, Ghent, Belgium; MAURIZIO CUTOLO*, MD, Full Professor of Rheumatology, Director, Research Laboratory and Academic Division of Clinical Rheumatology, Department of Internal Medicine, University of Genoa, Genoa, Italy. * Equal contribution to the manuscript. V. Smith is supported by a research grant of the Research Foundation - Flanders (Belgium; FWO; grant number: 1.5.217.13N) and she is Senior Clinical Investigator of the Research Foundation - Flanders (Belgium; FWO).

ClinicalTrials.gov Registration, clinicaltrials.gov, number NCT00379431. Address correspondence to Dr. V. Smith, Department of Rheumatology, Ghent University Hospital, Faculty of Medicine and Health Sciences, Department of Internal Medicine, Ghent University, De Pintelaan 185, B - 9000 Ghent, Belgium. E-mail: vanessa.smith@ugent.be

\section{REFERENCES}

1. Steen VD, Medsger TA Jr. Severe organ involvement in systemic sclerosis with diffuse scleroderma. Arthritis Rheum 2000; 43:2437-44.

2. Denton CP, Ong VH. Targeted therapies for systemic sclerosis. Nat Rev Rheumatol 2013;9:451-64.

3. Moazedi-Fuerst FC, Kielhauser SM, Brickmann K, Hermann J, Lutfi A, Meilinger M, et al. Rituximab for systemic sclerosis: arrest of pulmonary disease progression in five cases. Results of a lower dosage and shorter interval regimen. Scand J Rheumatol 2014;43:257-8.

4. Moazedi-Fuerst FC, Kielhauser SM, Bodo K, Graninger WB. Dosage of rituximab in systemic sclerosis: 2-year results of five cases. Clin Exp Dermatol 2015;40:211-2.

5. Fraticelli P, De Vita S, Franzolini N, Svegliati S, Scott CA, Tonnini $\mathrm{C}$, et al. Reduced type I collagen gene expression by skin fibroblasts of patients with systemic sclerosis after one treatment course with rituximab. Clin Exp Rheumatol 2015;33 Suppl 91:S160-7.

6. Smith V, Piette Y, van Praet JT, Decuman S, Deschepper E, Elewaut $\mathrm{D}$, et al. Two-year results of an open pilot study of a 2-treatment course with rituximab in patients with early systemic sclerosis with diffuse skin involvement. J Rheumatol 2013;40:52-7.

7. Smith V, Van Praet JT, Vandooren B, Van der Cruyssen B, Naeyaert JM, Decuman S, et al. Rituximab in diffuse cutaneous systemic sclerosis: an open-label clinical and histopathological study. Ann Rheum Dis 2010;69:193-7.

8. Koenig M, Joyal F, Fritzler MJ, Roussin A, Abrahamowicz M, Boire $\mathrm{G}$, et al. Autoantibodies and microvascular damage are independent predictive factors for the progression of Raynaud's phenomenon to systemic sclerosis: A twenty-year prospective study of 586 patients, with validation of proposed criteria for early systemic sclerosis. Arthritis Rheum 2008;58:3902-12.

9. Sulli A, Secchi ME, Pizzorni C, Cutolo M. Scoring the nailfold microvascular changes during the capillaroscopic analysis in systemic sclerosis patients. Ann Rheum Dis 2008;67:885-7.

10. Smith V, Pizzorni C, De Keyser F, Decuman S, Van Praet JT, Deschepper E, et al. Reliability of the qualitative and semiquantitative nailfold videocapillaroscopy assessment in a systemic sclerosis cohort: a two-centre study. Ann Rheum Dis 2010;69:1092-6.

J Rheumatol 2016;43:5 doi:10.3899/jrheum.151018 